\title{
LC-ESI-QTOF-MS/MS of Holoptelea integrifolia (Roxb.) Planch. leaves and in silico study of phenolic compounds' antiviral activity against the HSV1 virus.
}

\author{
Fatma S. Mahrous* ${ }^{*}$, Hala Sh. Mohammed ${ }^{1}$, Rehab Sabour ${ }^{2}$ and Lotfy D. Ismail ${ }^{3}$ \\ ${ }^{1}$ Department of Pharmacognosy, Faculty of Pharmacy (Girls), Al-Azhar University, Cairo, Egypt \\ ${ }^{2}$ Department of Medicinal Pharmaceutical Chemistry and Drug Design, Faculty of Pharmacy (Girls), Al-Azhar University, \\ Cairo, Egypt \\ ${ }^{3}$ Department of Pharmacognosy, Faculty of Pharmacy (Boys), Al-Azhar University, Cairo, Egypt \\ ${ }^{*}$ Correspondance: FatmaMahrous2098.el@azhar.edu.eg
}

Article history: Received: 2021-09-02 Revised: 2021-09-12 Accepted: 2021-09-16

\begin{abstract}
Holoptelea integrifolia (Roxb.) Planch. is a medicinal plant rich in phytochemicals that can be used to treat a number of ailments in humans and animals. In the current study, LC-ESI-QTOF-MS/MS technique was utilized for tentative identification of phenolic compounds in the ethyl-acetate extract of Holoptelea integrifolia (Roxb.) Planch. leaves. The 27 identified compounds were categorized as (15-flavonoids, 3-coumarins and 9-phenolic acids \& aldehydes) beside 4 unidentified compounds. In silico study of anti-viral activity against Herpes simplex virus type1(HSV-1) was performed to determine the possible binding modes of 27 compounds, which revealed docking scores ranging from ( -3.551 to $-9.385 \mathrm{kcal} \mathrm{mol}-1)$ comparable to that of Acyclovir and PNU-183792 with binding scores $6.476,-7.002$ respectively kcal mol-1. Acacetin-7-O-rutinoside (Linarin) (1), Chlorogenic acid (2), Kaempferol-3-Oarabinoside (8), Kaempferol-3-O-Glucuronide (23), Quercetin 3-O-galactoside (Hyperoside) (18), and Diosmin (29) displayed the highest binding scores with proper fitting via hydrogen bonds with some of the important key residues Gln616, Gln 617, Gln 618, Tyr696, Phe718, Ser720, Tyr722, Leu721 Gly819, Asn 815, and Asp888, all of which are crucial to the appropriate functioning of the DNA polymerase as one of the important therapeutic targets.
\end{abstract}

Keywords: Holoptelea integrifolia, HSV1, docking, acyclovir, LC, phenolic compounds, DNA polymerase \& antiviral

\section{INTRODUCTION}

Herpes simplex virus (HSV) infection is one of the most common infections of the oro-facial region. HSV-1 is a nuclear reproducing enveloped virus that is primarily contracted by direct contact with infected lesions or bodily fluids (typically saliva). In children, primary HSV-1 infections are either asymptomatic or cause mucocutaneous vesicular eruptions after a oneweek incubation period. Many people shed the Herpes simplex Virus Type 1 asymptomatically, making it a widespread infection all throughout the world. The link between shedding frequency, virus titer, and transmission, on the other hand, remains uncertain. A variety of antiviral medicines have been available for the treatment of HSV-1 infection in the last 20 years, but while they are usually effective, there is still a risk of drug-resistant strains emerging, and there is still no vaccination for this troublesome viral illness ${ }^{(1)}$.

Recently, some synthetic nucleoside analogues were used as anti-herpetic medicines in the early stages of infection, but they produced drug-resistant species, mainly in immunocompromised patients. As a result, there is a growing demand for novel antiviral agents, and pure plant-derived compounds have been demonstrated to exhibit antiviral action against HSV types. Their method of action was discovered to be either suppressing viral replication or viral genome synthesis. During infection of their host cell, HSV-1 and a variety of viruses use glycosaminoglycan (GAG) as initial attachment receptors. Polyphenols have been found to target HSV-1 glycoproteins that interact with GAGs, preventing them from interacting with cell surface GAGs and binding receptors (2). Furthermore herpes viruses encode conserved DNA polymerase which is required for viral replication and acts as one of the important therapeutic targets. Some drugs are able to inhibit the viral polymerase such as acyclic nucleoside analogs (e.g., acyclovir, gancyclovir, cidofovir, and penciclovir). Meanwhile nucleoside inhibitors have certain toxicity and probable drug-resistance, suggesting a need for finding nonnucleoside inhibitors (NNI) of herpes DNA polymerases ${ }^{(3)}$.

Many natural chemicals derived from medicinal plant extracts, such as phenolic compounds, terpenes

Cite this article: Mahrous, F., Mohammed, H., Sabour, R., ismail, L. LC-ESI-QTOF-MS/MS of Holoptelea integrifolia (Roxb.) Planch. leaves and In silico study of phenolic compounds' antiviral activity against the HSV1 virus. Azhar International Journal of Pharmaceutical and Medical Sciences, 2021; 1 (3): 91-101. doi: 10.21608/aijpms.2021.206682 
(mono-, di-, tri-), and glycosides, have been discovered to be promising anti-herpetic agents. The antiviral activity of Holoptelia integrifolia (Roxb.) Planch. against the Herpes simplex virus was significant (4). Holoptelea integrifolia (Roxb.) Planch. belongs to the Ulmaceae family and is found throughout the Northern Hemisphere's tropical and temperate regions, including the Indian Peninsula, Indo China, and Sri Lanka. The bark and leaves of this plant are used medicinally in the Ayurvedic system of medicine, primarily in the treatment of allergic illnesses, as well as oedema, diabetes, digestive disorders, and piles. Ringworm is treated with the seeds and stem bark paste, whereas scabies is treated with the latter. The plant's leaves are used to treat wounds on the outside. The fruit pulp crushed with black salt is used to treat menstruation irregularities. The astringent, digestive, antiinflammatory, carminative, depurative, laxative, and diuretic properties of the plant parts are widely employed. This plant has antiviral, antifungal, antimicrobial, antioxidant, anti-arthritic, woundhealing, anti-diabetic, anti-helminthic, antidiarrheal, antitumor, antiulcer, adaptogenic, hepatoprotective, analgesic and larvicidal properties. Terpenoids, glycosides, alkaloids, steroids, carbohydrates, sterols, saponins, proteins, tannins, and flavonoids are among the chemical constituents that have been confirmed by phytochemical analysis. Many chemical compounds were separated from the leaves and other sections of the plant, including sterols ( $\beta$-sitosterol, stigmasterol), triterpenes (friedelin, $\beta$-amyrin, oleanolic acid, hederagenin), and hydrocarbons (hexacosanol) ${ }^{(5,6)}$.

Phenolic compounds are one of the most abundant phytochemical constituents. Based on their chemical structure, they are known as phenolic acids, flavonoids, coumarins, lignans, stilbenes, and other compounds. They are found in practically all plants and have a high antioxidant capacity due to their molecular structures. Phenolic compounds also have a wide range of pharmacological properties ${ }^{(7)}$. Thus, the study aims to use liquid chromatography coupled by mass spectrometry (LC-ESI-QTOF-MS/MS) to recognize phenolic compounds in leaves of Holoptelea integrifolia (Roxb.) Planch. and evaluate a molecular docking of anti-herpetic activity study to determine the probable binding interactions inside the active site of DNA polymerase.

\section{METHODS}

\subsection{Collection\& identification}

Fresh leaves of Holoptelea integrifolia (Roxb.) Planch. were collected from the Zoo, Giza, Egypt during March and April (2018) (flowering stage). The plant was recognised by Dr. Therese Labib,
Botanical specialist, department of Flora and Taxonomy, El-Orman Garden, Giza, Egypt. A voucher specimen (Reg. No. H-5) of the plant was deposited in the pharmacognosy department's herbarium at Al-Azhar University's Faculty of Pharmacy in Cairo, Egypt.

\subsection{Preparation of plant extract}

Maceration of air-dried powder $(50 \mathrm{~g})$ in $70 \%$ aqueous ethanol $(3 \times 500 \mathrm{ml})$ at $(25 \pm 2)^{\circ} \mathrm{C}$., the extract was filtered, and the solvent was evaporated using a rotary evaporator (Buchi Co., Switzerland) at $50{ }^{\circ} \mathrm{C}$. To obtain semi-dried extract which re-extract with ethyl acetate $(2 \times 500 \mathrm{ml})$, filtered and evaporated to obtain $100 \mathrm{mg}$ semi-dried extract for chemical profiling.

\subsection{LC-ESI-QTOF-MS/MS}

LC-ESI-QTOF-MS/MS was accustomed to investigate the secondary metabolites of ethyl acetate extract of Holoptelea integrifolia (Roxb.) Planch. leaves. The temperature of the LC system was set to room temperature, $50 \mathrm{mg}$ of extract was dissolved in $1 \mathrm{~mL}$ of mobile phase A ( $5 \mathrm{mM}$ HCOONH4 buffer at $\mathrm{pH} 8$ in $1 \%$ methanol), vortexed for 2 minutes, then ultra-sonicated for 10 minutes, centrifugation for $5 \mathrm{~min}$ at $10000 \mathrm{rpm}$ phase then $20 \mu \mathrm{l} \operatorname{stock}(50 / 1000 \mu \mathrm{l})$ re diluted with $1000 \mu \mathrm{l}$ reconstitution solvent. Finally, the injected concentration was $1 \mu \mathrm{g} / \mu \mathrm{l}$. Mobile phase A (5 mM HCOONH4 buffer $\mathrm{pH} 8$ in 1 percent methanol) was subjected to a multi-step linear gradient, with the gradient increasing from (10-90) percent of mobile phase B. (100 percent acetonitrile) at a flow rate of $0.3 \mathrm{ml} / \mathrm{min}$ for 28 minutes. Columns; pre column In-Line filter disks $0.5 \mu \mathrm{m}$ x $3.0 \mathrm{~mm}$ (Phenomenex), column $\mathrm{X}$ select HSS T3 $2.5 \mu \mathrm{m}, 2.1 \times 150 \mathrm{~mm}$ (waters) Column temperature $40{ }^{\circ} \mathrm{C}$ were used for separation. Analyst software TF 1.7.1 (SCIEX) for LC-QTOF control, the injection volume in the UPLC system was $15 \mu \mathrm{L}$ for sample and mobile phase as the blank sample (8).

\subsection{Molecular docking}

The molecular docking research was performed via the Molecular Operating Environment (MOEDock 2014.09). Chemdraw was used to sketch the compounds' chemical structures and energy minimized, then introduced to MOE, where they were subjected to conformational search. Their threedimensional conformers were docked into the active site of DNA polymerase enzyme (PDB ID: 7LUF). During the docking process, London $\mathrm{dG}$ was set aside for ranking and the GBVI/WSA dG (Generalized-Born Volume Integral/Weighted Surface Area) was used for scoring of the generated poses. The water molecules were removed throughout the docking process. The missing hydrogen atoms were kept in order to assign the right 
ionization states to the protein structure. To achieve molecular docking, the "Docking" module in MOE was used. The docking process was carried out by default.
London $\mathrm{dG}$ ranked the top 30 poses and stored them. The data were analyzed and visualized using the "Ligand Interactions" tool, which displayed the binding modalities in the active site of these compounds.

\section{RESULTS}

\subsection{LC-ESI-QTOF-MS/MS Annotation of phenolic compounds}

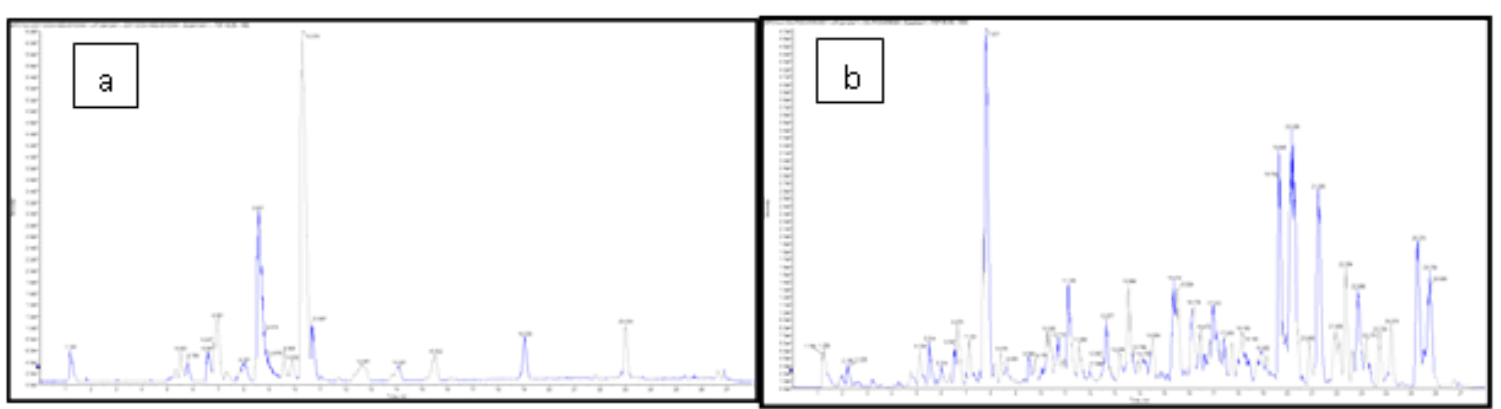

Figure (1): Negative (a) \& positive (b) mode LC-ESI-QTOF-MS/MS chromatograms peak numbers agree with those in Table (1)

In the current study, the phenolic 2ry metabolites in Holoptelea integrifolia (Roxb.) Planch. leaves ethyl acetate extract was identified using LC-ESI-QTOF-MS/MS. The Rt, full MS spectra, and MSn were used to determine the limit of detection for each peak of compounds. By comparing reference compounds spectra and literature, fragmentation patterns in negative and positive mode were revealed 4 unidentified compounds beside 27 compounds were identified tentatively in Holoptelea integrifolia (Roxb.) Planch. leaves ethyl acetate extract and characterized as Flavonoids; Acacetin-7-O- rutinoside (Linarin) (1), Eriodictyol-7-O-glucoside (3), Kaempferol-3-Oarabinoside (8), Quercetin (11), 35 7- trihydroxy-4'methoxyflavone (Kaempferide) (13), Quercetin 3-Ogalactoside (Hyperoside) (18), Syringetin-3-O- galactoside (21), Kaempferol-3-O-glucuronide (23), Baicalein-7-O-glucuronide (24), Malvidin-3O-galactoside (25), $3 \quad 3^{\prime} \quad 4^{\prime} \quad$ 5-tetrahydroxy-7methoxyflavone (Rhamnetin) (27), Eriodictyol-7-Oneohesperidoside (28), Diosmin (29), Neohesperidin dihydrochalcone (30) and Peonidin-3,5-O-diglucopyranoside (31). Coumarins; Scopoletin (6) Delphnetin (14) and 7-Hydroxy-4-methylcoumarin (Hymecromone) (17). Phenolic acids \& aldehydes; Chlorogenic acid (2), Cinnamic acid (4), Cinnamaldehyde (7), Syringaldehyde (9), 4Hydroxy-3-methoxycinnamaldehyde (Coniferyl aldehyde) (15), 3-(4-Hydroxy-3,5dimethoxyphenyl)-2-propenoic acid (Sinapic acid) (16), Caffiec acid (20) and Sinapyl aldehyde (22). Phenols; paranitrophenol (5).

Table (1): Phenolic compounds in Holoptelea integrifolia (Roxb.) Planch. leaves ethyl acetate extract tentatively by negative and positive mode LC-ESI-QTOF-MS/MS

\begin{tabular}{|c|c|c|c|c|}
\hline No & $\mathbf{R t}$ & {$[\mathbf{M}-\mathbf{H}]^{-} /[\mathbf{M}+\mathbf{H}]^{+}$} & Major product ions (m/z) & Tentatively identified compounds \\
\hline 1. & 5.52 & $591.16[\mathrm{M}-\mathrm{H}]^{-}$ & $\begin{array}{lllll}522.88 & 454.90 & 386.93 & 316.95 & 248.96\end{array}$ & Acacetin-7-O-rutinoside (Linarin) \\
\hline 2. & 5.78 & $353.10[\mathrm{M}-\mathrm{H}]^{-}$ & $288.03,207.05,199.80,179.03$ & Chlorogenic acid \\
\hline 3. & 6.57 & $449.09[\mathrm{M}-\mathrm{H}]^{-}$ & Not fragmented & Eriodictyol-7-O-glucoside \\
\hline 4. & 6.66 & $149.09[\mathrm{M}+\mathrm{H}]^{+}$ & $\begin{array}{llll}131.09 & 121.02 & 109.01 & 105.0693 .06 \\
81.07 & & & \\
69.03 & 53.03 & & \\
\end{array}$ & Trans-Cinnamate (Cinnamic acid) \\
\hline 5. & 6.94 & $138.01[\mathrm{M}-\mathrm{H}]^{-}$ & 108.0292 .02 & Para nitrophenol \\
\hline 6. & 7.10 & $193.04[\mathrm{M}+\mathrm{H}]^{+}$ & $\begin{array}{lllll}178.02 & 150.03 & 132.9 & 122.03 & 104.9 \\
93.7 & & & & \\
9\end{array}$ & Scopoletin \\
\hline
\end{tabular}




\begin{tabular}{|c|c|c|c|c|}
\hline No & $\mathbf{R t}$ & {$[\mathbf{M}-\mathrm{H}]^{-/[}[\mathbf{M}+\mathbf{H}]^{+}$} & Major product ions (m/z) & Tentatively identified compounds \\
\hline 7. & 7.80 & $133.10[\mathrm{M}+\mathrm{H}]^{+}$ & $\begin{array}{llllll}15.05 & 105.06 & 79.06 & 77.03 & 51.02\end{array}$ & Cinnamaldehyde \\
\hline 8. & 8.64 & $417.11[\mathrm{M}-\mathrm{H}]^{-}$ & $371.2 \quad 348.92 \quad 285.07 \quad 218.96$ & Kaempferol-3-O-arabinoside \\
\hline 9. & 8.85 & $181.04[\mathrm{M}-\mathrm{H}]^{-}$ & $\begin{array}{lllll}166.02 & 154.02 & 151.01 & 136.98 & 112.98 \\
\end{array}$ & Syringaldehyde \\
\hline 10. & 8.97 & $333.09[\mathrm{M}-\mathrm{H}]^{-}$ & $\begin{array}{lllll}288.95 & 220.97 & 163.04 & 115.66\end{array}$ & Unidentified \\
\hline 11. & 9.50 & $303.09[\mathrm{M}+\mathrm{H}]^{+}$ & 257.05229 .01 & Quercetin \\
\hline 12. & 9.58 & $152.03[\mathrm{M}-\mathrm{H}]^{-}$ & $\begin{array}{llllll}135.03 & 121.02 & 107.03 & 93.03 & 78.03\end{array}$ & Unidentified \\
\hline 13. & 9.97 & $299.05[\mathrm{M}-\mathrm{H}]^{-}$ & 284.02225 .1 & $\begin{array}{l}35 \text { 7-trihydroxy-4'-methoxy- } \\
\text { flavone (Kaempferide) }\end{array}$ \\
\hline 14. & 10.30 & $177.05[\mathrm{M}-\mathrm{H}]^{-}$ & $\begin{array}{lllll}162.03 & 145.02 & 121.02 & 118.66 & 117.07\end{array}$ & Daphnetin \\
\hline 15. & 10.36 & $179.10[\mathrm{M}+\mathrm{H}]^{+}$ & $\begin{array}{lllll}161.09 & 147.04 & 122.03 & 119.04 & 91.1 \\
65.03 & & & & \end{array}$ & $\begin{array}{l}\text { 4-Hydroxy-3- } \\
\text { methoxycinnamaldehyde(Coniferyl } \\
\text { aldehyde) }\end{array}$ \\
\hline 16. & 10.67 & $223.05[\mathrm{M}-\mathrm{H}]^{-}$ & 191.06 & $\begin{array}{l}\text { 3-(4-Hydroxy-3,5-dimethoxyphenyl)- } \\
\text { 2- propenoic acid (Sinapic acid) }\end{array}$ \\
\hline 17. & 10.73 & $177.05[\mathrm{M}+\mathrm{H}]^{+}$ & $\begin{array}{lllll}149.05 & 145.02 & 134.03 & 117.03 & 89.03 \\
78.04 & & & & \\
77.03 & 53.02 & & & \\
\end{array}$ & $\begin{array}{l}\text { 7-Hydroxy-4-methylcoumarin } \\
\text { (Hymecromone) }\end{array}$ \\
\hline 18. & 11.15 & $465.18[\mathrm{M}+\mathrm{H}]^{+}$ & Not fragmented & $\begin{array}{l}\text { Quercetin 3-O-galactoside } \\
\text { (Hyperoside) }\end{array}$ \\
\hline 19. & 12.66 & $294.21[\mathrm{M}-\mathrm{H}]^{-}$ & Not fragmented & Unidentified \\
\hline 20. & 12.67 & $181.12[\mathrm{M}+\mathrm{H}]^{+}$ & $\begin{array}{llll}163.04 & 141.04 & 77.01 & 54.01\end{array}$ & Caffeic acid \\
\hline 21. & 13.78 & $509.20[\mathrm{M}+\mathrm{H}]^{+}$ & Not fragmented & Syringetin-3-O-galactoside \\
\hline 22. & 14.53 & $209.11[\mathrm{M}+\mathrm{H}]^{+}$ & $\begin{array}{lllll}149.04 & 125.09 & 112.07 & 98.06 & 84.08 \\
70.06 & & & & \\
\end{array}$ & Sinapyl aldehyde \\
\hline 23. & 15.59 & $461.09[\mathrm{M}-\mathrm{H}]^{-}$ & 314.96285 .07 & Kaempferol-3-O-glucuronide \\
\hline 24. & 18.15 & $447.08[\mathrm{M}+\mathrm{H}]^{+}$ & 430.2271 .05 & Baicalein-7-O-glucuronide \\
\hline 25. & 18.99 & $493.12[\mathrm{M}+\mathrm{H}]^{+}$ & Not fragmented & Malvidin-3-O-galactoside \\
\hline 26. & 19.03 & $327.28[\mathrm{M}-\mathrm{H}]^{-}$ & 59.01 & Unidentified \\
\hline 27. & 19.72 & $317.11[\mathrm{M}+\mathrm{H}]^{+}$ & 302.11224 .17 & $\begin{array}{l}3 \text { 3' 4' 5-tetrahydroxy-7- } \\
\text { methoxyflavone (Rhamnetin) }\end{array}$ \\
\hline 28. & 21.92 & $597.22[\mathrm{M}+\mathrm{H}]^{+}$ & $\begin{array}{l}595.4563 .25 \\
475.23\end{array}$ & $\begin{array}{l}\text { Eriodictyol-7- } O \text {-neohesperidoside } \\
\text { (Neoeriocitrin) }\end{array}$ \\
\hline 29. & 22.83 & $609.26[\mathrm{M}+\mathrm{H}]^{+}$ & $\begin{array}{rrrrr}591.21 & 577.25 & 563.25 & 503.24 & 485.22 \\
470.20 & 401.27 & 209.15 & 149.09 & 133.09 \\
\end{array}$ & Diosmin \\
\hline 30. & 23.06 & $611.14[\mathrm{M}-\mathrm{H}]^{-}$ & 269.04 & Neohesperidin dihydrochalcone \\
\hline 31. & 23.72 & $625.29[\mathrm{M}+\mathrm{H}]^{+}$ & $\begin{array}{lllll}566.29 & 501.22 & 459.20 & 405.21 & 301.15 \\
223.09 & 193.19 & 166.08 & 145.10 & \\
\end{array}$ & Peonidin-3,5-O-di- glucopyranoside \\
\hline
\end{tabular}

3.2. Molecular Docking study

The results are displayed in Table 2 and Figures 2-10.

Table (2) The docking results of Phenolic compounds tentatively identified from ethyl-acetate extract of Holoptelia integrifolia (Roxb.) Planch. into the active site of Herpes simplex 1 DNA polymerase.

\begin{tabular}{llcl}
\hline No. & Compound & $\begin{array}{c}\text { Docking } \\
\text { score } \\
\text { (kcal/mol) }\end{array}$ & Interacting residues \\
\hline $\mathbf{1}$ & Acacetin-7-O-rutinoside (Linarin) & -9.385 & Asn815,Asp888,Gln617, Gly819,Leu721,Tyr722 \\
\hline $\mathbf{2}$ & Chlorogenic acid & -8.110 & Asn815, Asp888, Gln617, Phe718, Tyr722 \\
\hline $\mathbf{3}$ & Eriodictyol-7-O-glucoside & -6.016 & Gln617, Gln618 \\
\hline $\mathbf{4}$ & Trans-Cinnamate (Cinnamic acid) & -7.145 & Asn815, Tyr722 \\
\hline $\mathbf{5}$ & Para nitrophenol & -6.772 & Asn815, Asp888 \\
\hline $\mathbf{6}$ & Scopoletin & -6.133 & Gln617, Gln618 \\
\hline $\mathbf{7}$ & Cinnamaldehyde & -4.224 & $\mathrm{Gln} 617, \mathrm{Gln} 618$ \\
\hline $\mathbf{8}$ & Kaempferol-3-O- arabinoside & -8.172 & $\mathrm{Gln} 617, \mathrm{Gln} 618, \mathrm{Gly} 822, \mathrm{Tyr} 696$ \\
\hline $\mathbf{9}$ & Syringaldehyde & -3.551 & $\mathrm{Gln} 618$ \\
\hline
\end{tabular}




\begin{tabular}{llcl}
\hline No. & Compound & $\begin{array}{c}\text { Docking } \\
\text { score } \\
\text { (kcal/mol) }\end{array}$ & Interacting residues \\
\hline $\mathbf{1 1}$ & Quercetin & -6.853 & Asn815, Gly819 \\
\hline $\mathbf{1 3}$ & $\begin{array}{l}\text { 3 5 7-trihydroxy-4'-methoxy-flavone } \\
\text { (Kaempferide) }\end{array}$ & -5.716 & Asn815, Thr887 \\
\hline $\mathbf{1 4}$ & Daphnetin & -5.298 & Asn815, Asp888, Ser720 \\
\hline $\mathbf{1 5}$ & $\begin{array}{l}\text { 4-Hydroxy-3-methoxycinnamaldehyde } \\
\text { (Coniferyl aldehyde) }\end{array}$ & -5.066 & Asp888, Tyr722 \\
\hline $\mathbf{1 6}$ & $\begin{array}{l}\text { 3-(4-Hydroxy-3,5-dimethoxyphenyl)- } \\
\text { 2-propenoic acid (Sinapic acid) }\end{array}$ & -7.270 & Asn815, Asp888 \\
\hline $\mathbf{1 7}$ & $\begin{array}{l}\text { 7-Hydroxy-4-methylcoumarin } \\
\text { (Hymecromone) }\end{array}$ & -5.001 & Leu721, Tyr722 \\
\hline $\mathbf{1 8}$ & $\begin{array}{l}\text { Quercetin 3-O-galactoside } \\
\text { (Hyperoside) }\end{array}$ & -9.021 & Gln616, Gln617, Gln618 \\
\hline $\mathbf{2 0}$ & Caffeic acid & -5.779 & Asn815, Asp888 \\
\hline $\mathbf{2 1}$ & Syringetin-3-O-galactoside & -5.425 & Asn815, Gln617 \\
\hline $\mathbf{2 2}$ & Sinapyl aldehyde & -4.019 & Gln617 \\
\hline $\mathbf{2 3}$ & Kaempferol-3-O-glucuronide & -8.239 & Asn815, Asp888, Phe718, Ser720 \\
\hline $\mathbf{2 4}$ & Baicalein-7-O-glucuronide & -5.889 & Asn815, Gln617 \\
\hline & & & \\
\hline
\end{tabular}

\section{DISCUSSION}

4.1. Annotation of phenolic compounds in Holoptelia integrifolia (Roxb.) Planch. ethyl-acetate extract using LC-ESI-QTOF-MS/MS

Flavonoids ; Compound (1) was detected at Rt $5.52 \mathrm{~min}$, it showed a deprotonated ion $[\mathrm{M}-\mathrm{H}]-$ at $\mathrm{m} / \mathrm{z}$ $591.16 \mathrm{mu}$, with characteristic MS2 fragment ion at $\mathrm{m} / \mathrm{z} 283$ [M-H-rutinoside]- which related to deprotonated acacetin and consequently it was tentatively identified as Acacetin-7-O-rutinoside (Linarin) (9).Acacetin was identified on the basis of its product ion scan spectrum, showing the [A CH3]- $\mathrm{m} / \mathrm{z} 268$, [A - COCH3]- m/z 240, and m/z 211 (10). Compound (8) was detected at Rt $8.64 \mathrm{~min}$, it showed a deprotonated ion $[\mathrm{M}-\mathrm{H}]-$ at $\mathrm{m} / \mathrm{z} 417.11 \mathrm{mu}$, and it showed a diagnostic fragment ion of Kaempferol at m/z 285 attributed to the elimination of an arabinoside residue, it could be identified as Kaempferol-3-O-arabinoside (11). Compound (11) was detected at Rt $9.5 \mathrm{~min}$., in the positive ionization mode it showed a protonated ion $[\mathrm{M}+\mathrm{H}]+$ at $\mathrm{m} / \mathrm{z}$ $303.09 \mathrm{mu}$ and a diagnostic fragment ion at $\mathrm{m} / \mathrm{z}$ $257.05 \mathrm{mu}$ corresponding to the loss of $\mathrm{CO} 2$ moiety $(-\mathrm{m} / \mathrm{z} 44 \mathrm{mu})[\mathrm{M}+\mathrm{H}-\mathrm{CO} 2]+$, at $\mathrm{m} / \mathrm{z} 229$ formed after loss of both $\mathrm{CO}$ and $\mathrm{CO} 2$ groups, it could be identified as Quercetin (12). Compound (23) was detected at Rt $15.59 \mathrm{~min}$, it showed a deprotonated ion $[\mathrm{M}-\mathrm{H}]-$ at $\mathrm{m} / \mathrm{z} 461.11 \mathrm{mu}$, and it showed a diagnostic fragment ion of Kaempferol at m/z 285 attributed to the elimination of a glucuronide residue, it could be identified as Kaempferol-3-Oglucuronide (10). Compound (27) was detected at Rt $19.72 \mathrm{~min}$., in the positive ionization mode it showed a protonated ion $[\mathrm{M}+\mathrm{H}]+$ at $\mathrm{m} / \mathrm{z} 317.11 \mathrm{mu}$ and its demethylated fragment $[(\mathrm{M}+\mathrm{H})-15]+$ at 302.11 , it could be identified as $33^{\prime} 4^{\prime}$ 5- tetrahydroxy-7methoxyflavone (Rhamnetin) (13).

Coumarins; Compound (6) was detected at Rt $7.10 \mathrm{~min}$. , in the positive ionization mode it showed a protonated ion $[\mathrm{M}+\mathrm{H}]+$ at $\mathrm{m} / \mathrm{z} 193.2 \mathrm{mu}$, characterized by successive loss of $[\mathrm{M}+\mathrm{H}-$ $\mathrm{COCH} 3 \mathrm{OH}]+$ leading to the characteristic key ion at $\mathrm{m} / \mathrm{z} 132.9$, it could be identified as Scopoletin (14). Compound (14) was detected at Rt $10.30 \mathrm{~min}$, it showed a deprotonated ion $[\mathrm{M}-\mathrm{H}]-$ at $\mathrm{m} / \mathrm{z} 177 \mathrm{mu}$, and it showed a diagnostic fragment ion at $\mathrm{m} / \mathrm{z}$ $162.03,145.02,121.02,118.04$ and $117.03 \mathrm{mu}$ were characteristic for coumarin type, it was tentatively identified as Daphnetin (15). Phenolic acids \& aldehydes; Compound (9) was detected at Rt 8.85 min, it showed a deprotonated ion $[\mathrm{M}-\mathrm{H}]-$ at $\mathrm{m} / \mathrm{z}$ $181.04 \mathrm{mu}$ along with major fragmentation peaks at $\mathrm{m} / \mathrm{z}, 166.02$ and 151.01 , it could be identified as Syringaldehyde (16). Compound (16) was detected at Rt $10.67 \mathrm{~min}$, it showed a deprotonated ion [M-H]at $\mathrm{m} / \mathrm{z} 233.05 \mathrm{mu}$, it could be identified as 3-(4Hydroxy- 3,5-dimethoxyphenyl)-2-propenoic acid (Sinapic acid)(17). Compound (20) was detected at Rt 12.67 min., in the positive ionization mode it showed a protonated ion $[\mathrm{M}+\mathrm{H}]+$ at $\mathrm{m} / \mathrm{z} 181.12 \mathrm{mu}$ characterized by successive loss of $[\mathrm{M}+\mathrm{H}-\mathrm{H} 2 \mathrm{O}]+$ leading to the characteristic key ion at $\mathrm{m} / \mathrm{z} 163.0$, it could be identified as Caffeic acid (18). Compound (22) was detected at Rt 14.53 min., in the positive ionization mode it showed a protonated ion $[\mathrm{M}+\mathrm{H}]+$ at $\mathrm{m} / \mathrm{z} 209.11 \mathrm{mu}$, it could be identified as Sinapyl aldehyde (19). Phenols; Compound (5) was detected at Rt $6.94 \mathrm{~min}$, it showed a deprotonated ion [M-H]- 
at $\mathrm{m} / \mathrm{z} 138.01 \mathrm{mu}$ along with major fragmentation peaks at $\mathrm{m} / \mathrm{z}, 108.02,92.02,80,64$, and 38, it could be identified as para nitrophenol (20).

4.2. The docking results of phenolic compounds tentatively identified form Holoptelia integrifolia

(Roxb.) Planch. ethyl-acetate extract into the active site of Herpes simplex 1 DNA polymerase Human herpes viruses are considered causative agents for different transmitted infections in human. Drug targets are mostly proteins belong to both families of glycoprotein and DNA polymerase. Herpes viruses share common replication cycle where viral polymerase (POL) functions at several points, As a result, it's an appealing target for antiherpetic medication development. The Herpes virus polymerases range in size from 1012 to 1242 amino acids and display about $34-90 \%$ primary sequence identity. Herpes simplex 1 DNA polymerase is considered the prototype for the herpes virus POL family, having 1235 amino acids displaying all the enzymatic tasks of a polymerase $(21,22)$. Among the common therapies for herpes viral infections the nucleoside analogs acyclovir that target the viral DNA polymerase, which is essential for viral DNA replication. Herein, a molecular docking study by the MOE program(3) was performed to predict and score the poses of the protein-ligand binding using the structure of the HSV-1 POL (PDB ID: 7LUF) downloaded from the protein data bank(23). First redocking of PNU183792 (the crystallized ligand) was carried out for validation. It showed a docking score value of -7.002 $\mathrm{kcal} / \mathrm{mol}$ with a root-mean-square deviation (RMSD) value of $1.02 \AA$. A hydrogen bonding with the key residues Asp888, Gln617 was observed in addition to arene-H interaction with Leu721.The tested compounds were able to form H-bonds with some of the most important amino acids (Gln616, Gln617, Gln618, Tyr696, Phe718, Ser720, Leu721, Tyr722,
Asn815, Gly819, Thr887, Asp888) inside the active site, which can rationalize the potent activity confirmed by the docking scores and their binding poses. The binding mode of acyclovir showed interactions with the highly conserved residues (Asn815, Phe718, Tyr722) present in the binding cleft to block the viral DNA replication. Furthermore, the residues Phe718, Tyr722, Pro723 and Tyr818 provided significant hydrophobic contacts. Moreover, Gln617, Gln618, Asn815 and Tyr818 play an important part in the ligand's stability and all of those are necessary for the polymerase to work properly (24). Among the docked compounds, it was found that three of the flavonoid-3-Oglycosides [(Kaempferol-3-O- arabinoside (8), Kaempferol-3-O-glucuronide (23) and Hyperoside (18)] exerted high binding affinities via forming hydrogen bonds with the key residues of the active site with docking score values $=-8.172,-8.239$, $9.021 \mathrm{kcal} / \mathrm{mol}$ respectively. Moreover the flavonoid7-O- glycosides (Linarin)(1) displayed arene-H interactions with both Tyr722, Gly819, in addition to four H-bonds with Gln617, Asn815, Asp888 and Leu721 revealing the highest binding score -9.385 $\mathrm{kcal} / \mathrm{mol}$. Interestingly Diosmin(29) belonging to the same group exhibited four H-bonds with the same amino acids (Leu721, Tyr722, Asn815, Asp888) with binding score $=-9.211 \mathrm{kcal} / \mathrm{mol}$. Concerning the phenolic acids, Chlorogenic acid (2) was the most bonded compound to the active site via four $\mathrm{H}$-bonds with the amino acids Gln617, Asn815, Asp888 and Phe718, together with arene-H interactions with Tyr722. Interestingly coumarin compounds [(Daphnetin (14), Scopoletin (6), Hymecromone (17)] revealed good affinities with high binding scores $-5.298,-6.133 \&-5.001$ respectively. The best poses were those in which the compounds had a binding mode (conformation and orientation) that was more similar to PNU- 183792.5.

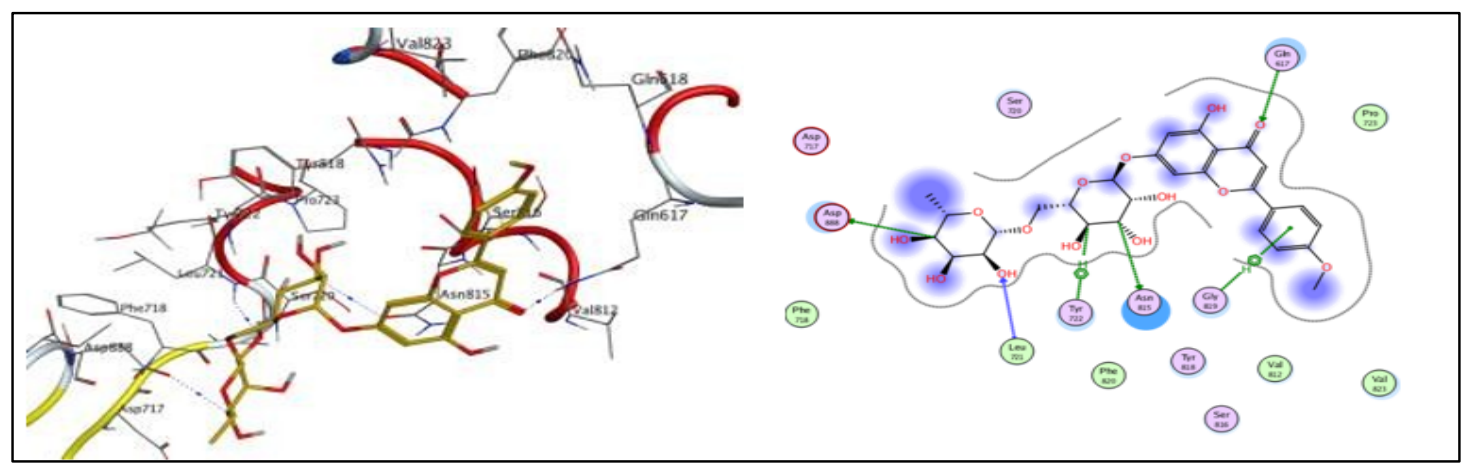

Figure (2): The two-dimensional and three-dimensional suggested binding mode of Acacetin-7-O- rutinoside (Linarin) (1) inside DNA polymerase 


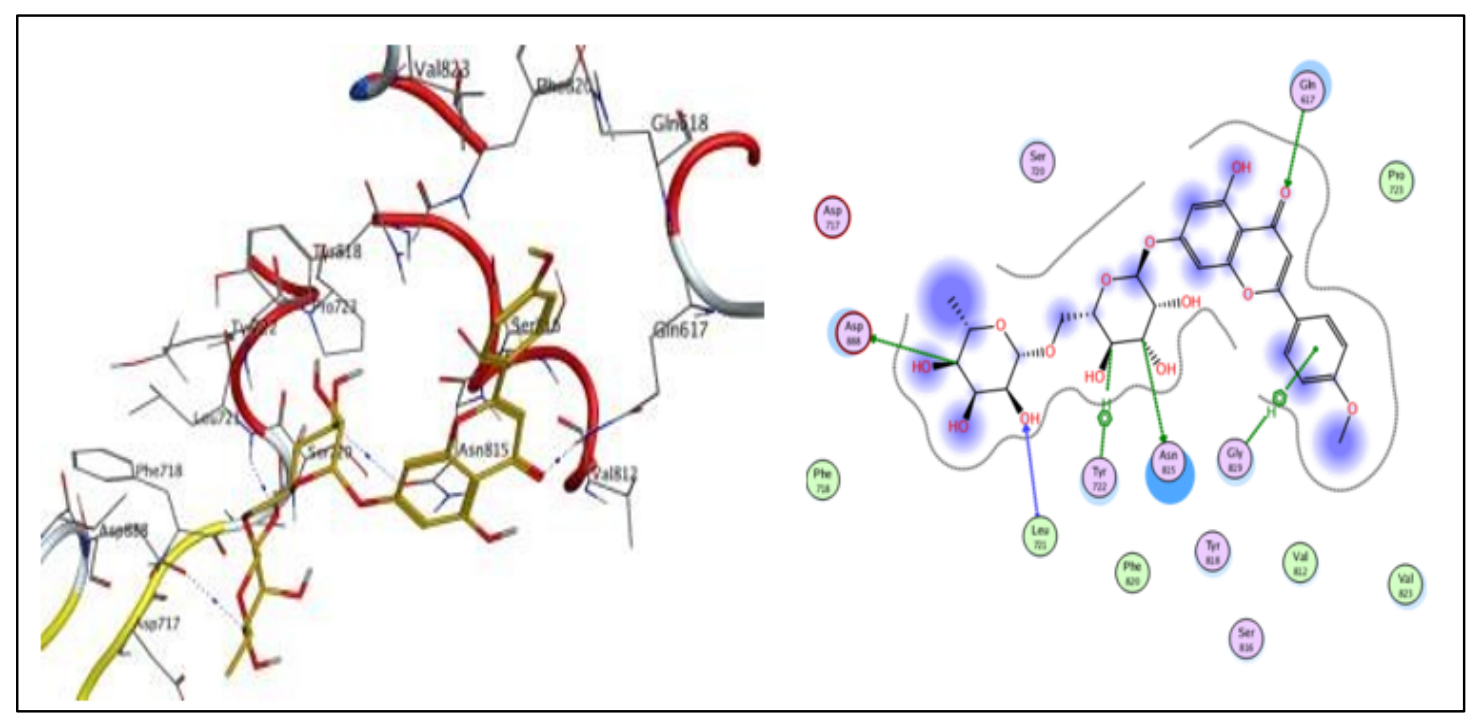

Figure (3): The two-dimensional and three-dimensional suggested binding mode of Chlorogenic acid (2) inside DNA polymerase

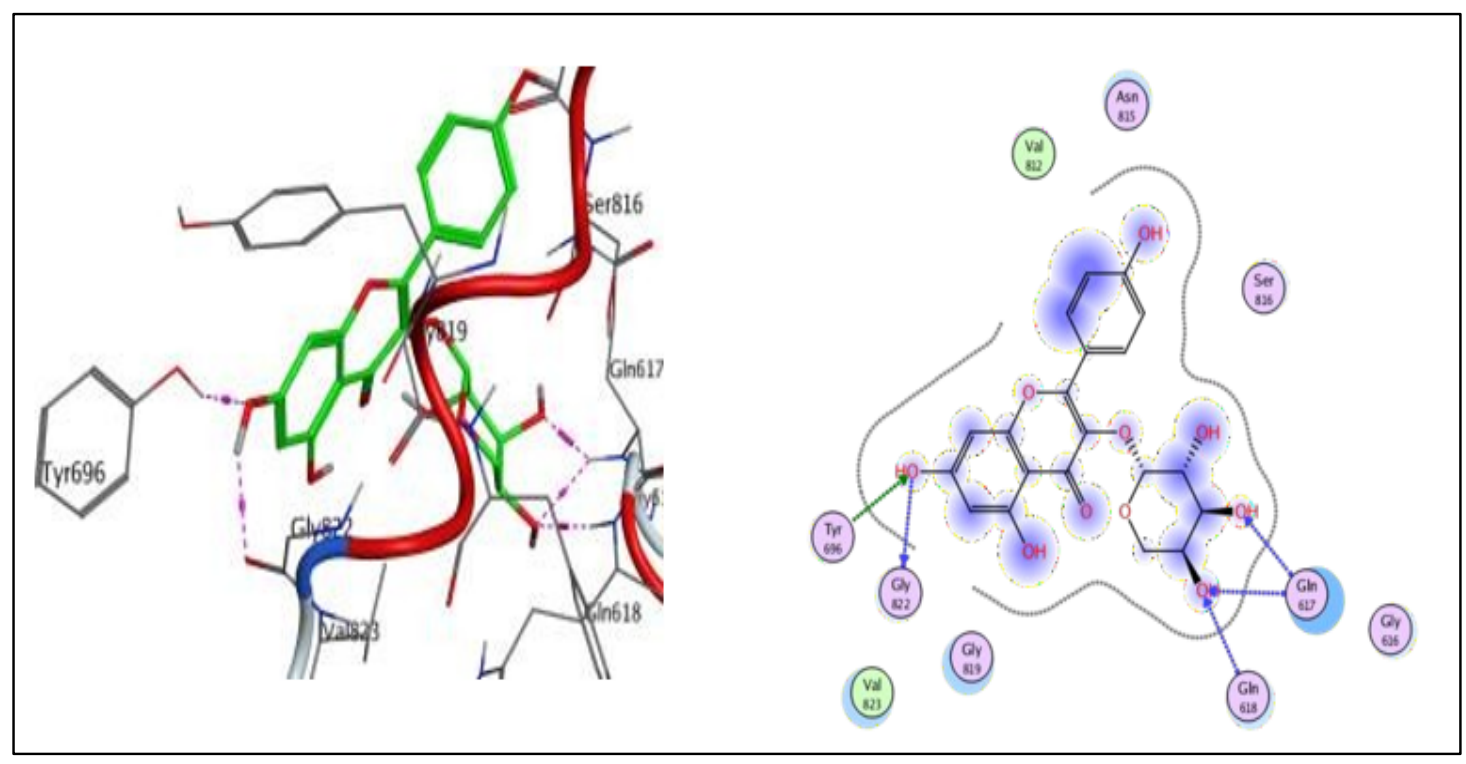

Figure (4): The two-dimensional and three-dimensional suggested binding mode of Kaempferol- 3-O- arabinoside (8) inside DNA polymerase 


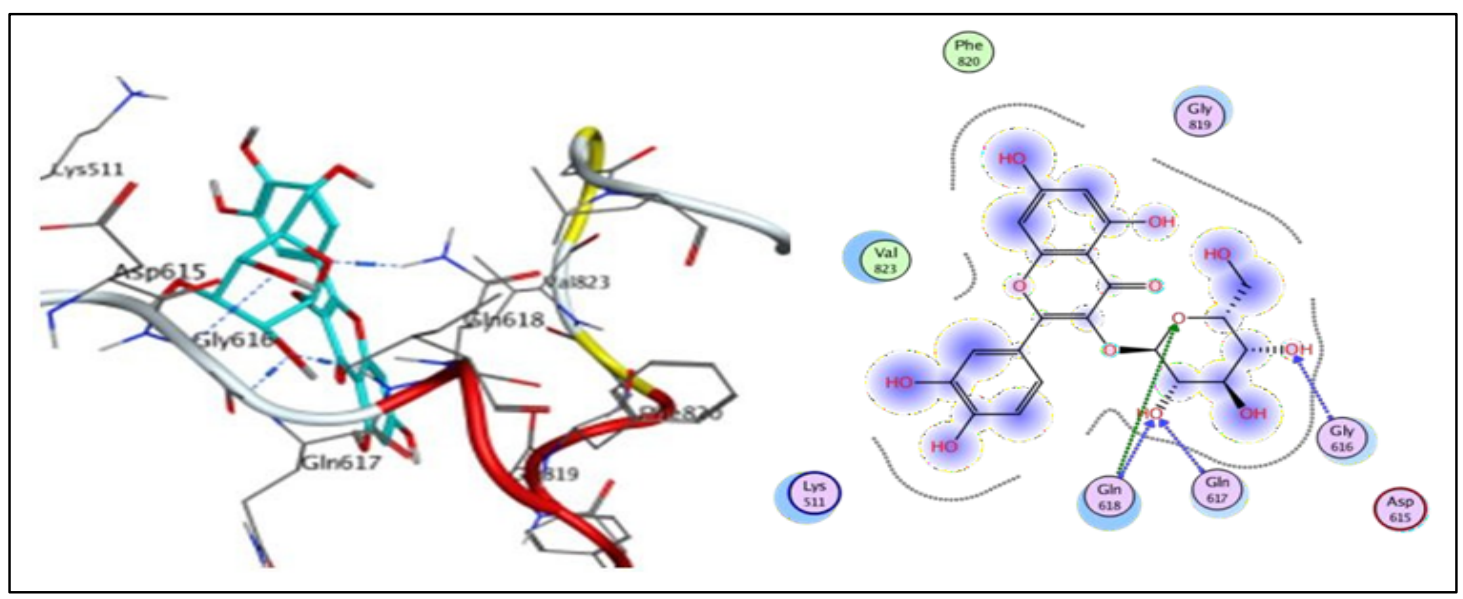

Figure (5): The two-dimensional and three-dimensional suggested binding mode of Quercetin 3$O$-galactoside (Hyperoside) (18) inside DNA polymerase

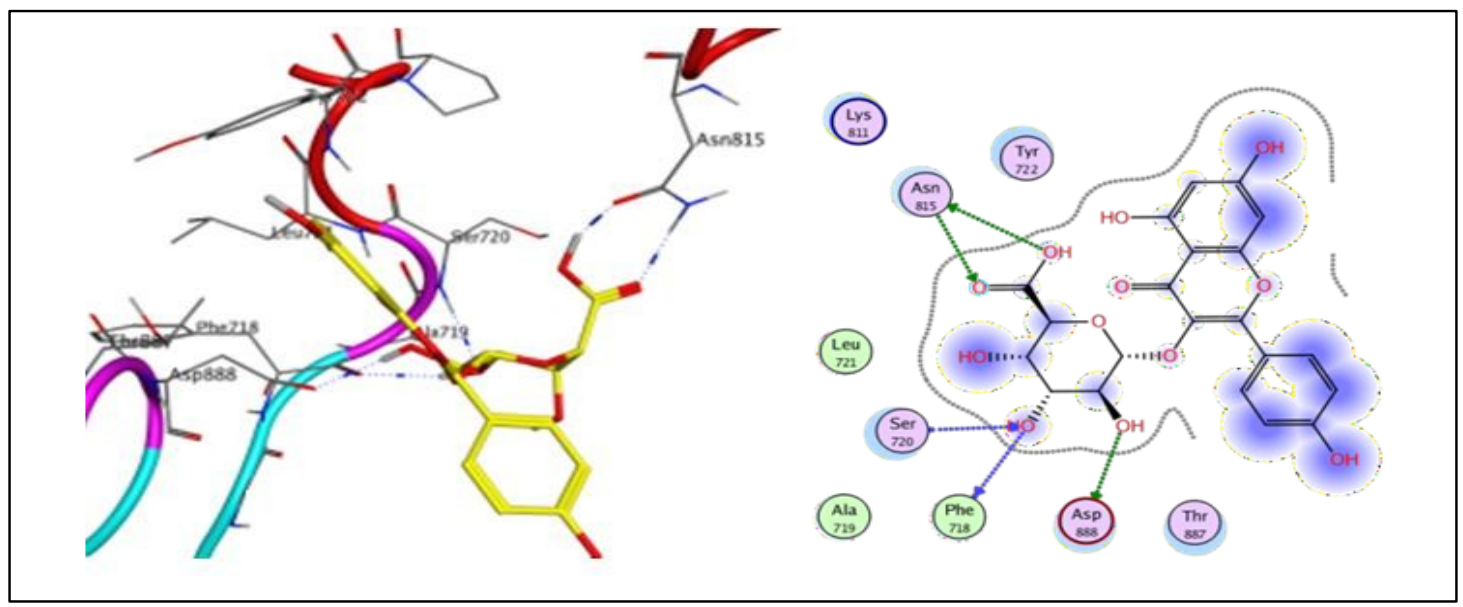

Figure (6): The two-dimensional and three-dimensional suggested binding mode of Kaempferol- 3-Oglucuronide (23) inside DNA polymerase

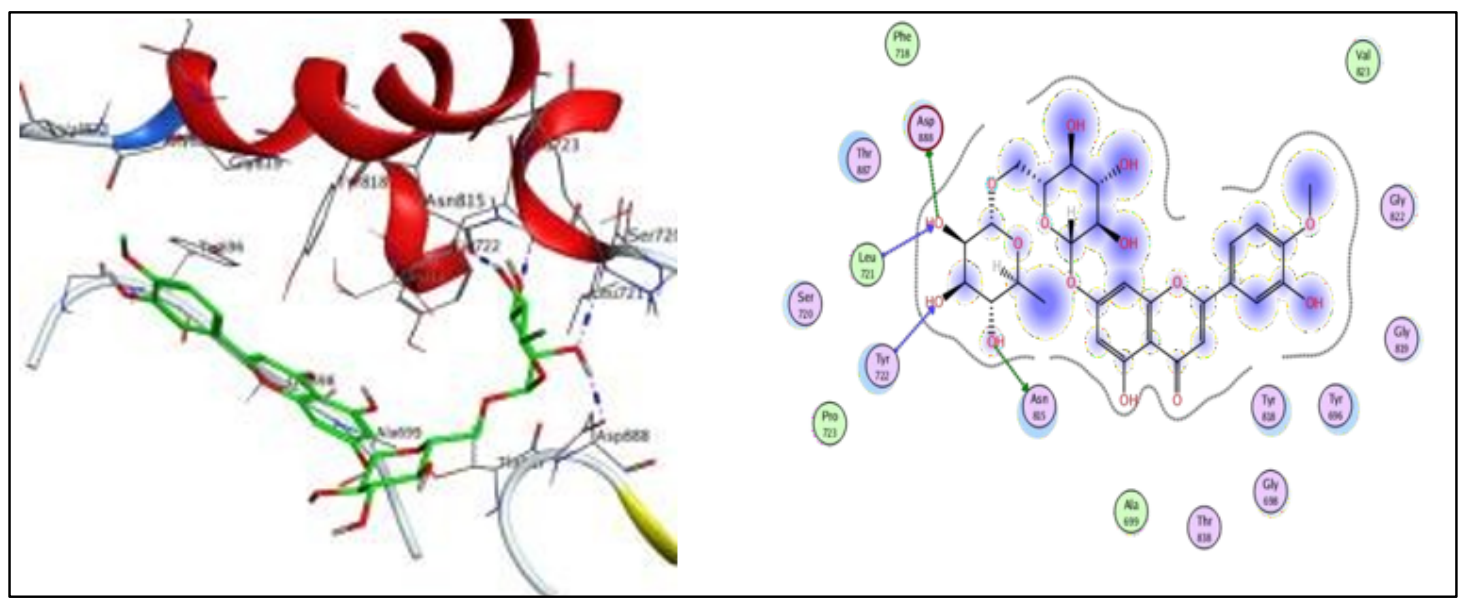

Figure (7): The two-dimensional and three-dimensional suggested binding mode of Diosmin (29) inside DNA polymerase 


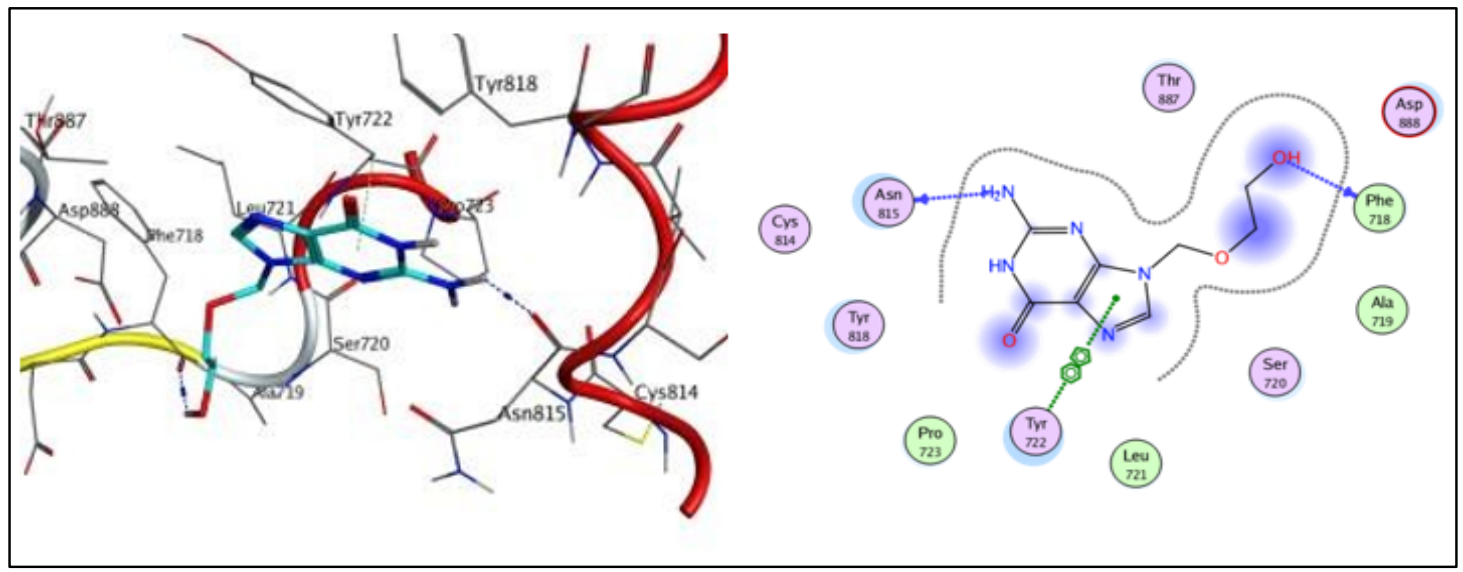

Figure (8): The two-dimensional and three-dimensional suggested binding mode of Acyclovir inside DNA polymerase

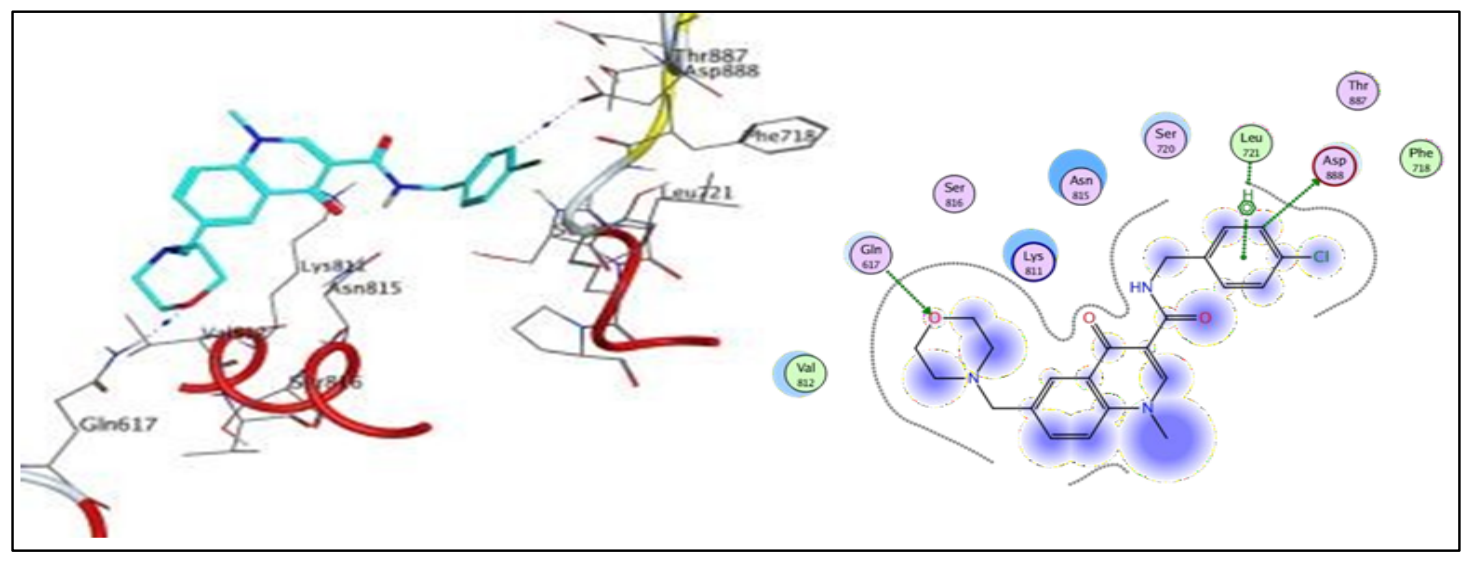

Figure (9): The two-dimensional and three-dimensional suggested binding mode of PNU-183792 inside DNA polymerase

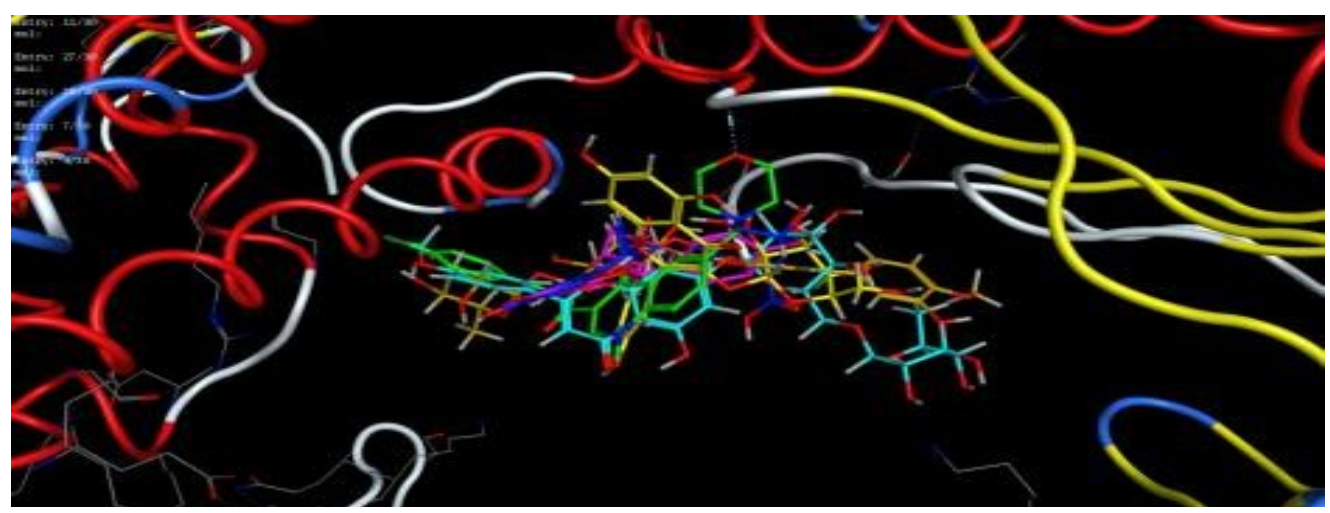

Figure (10): The Best docking poses for compounds 8 (yellow), 23 (magenta), 18 (blue), 1 (orange), 29 (cyan), 2 (brown) and PNU-183792 (1) (green) inside the HSV-1 DNA polymerase in complex with PNU-183792

\section{CONCLUSION}

Human Herpes simplex viruses (HSV-1 and -2) are prevalent human infections that continue to pose 
a severe health risk. The hunt for an integrated management strategy for HSV infections has piqued people's curiosity in recent years. Acyclovir and related nucleoside analogues have been approved for viral DNA polymerase treatment. Despite the fact that these medications are now effective against HSV infections, their widespread use has resulted in the emergence of drug-resistant variants. As a result, finding new sources to produce novel antiherpetic drugs has become a top priority for resolving the problem. Natural products as prospective novel antiHSV medications provide a number of benefits, including fewer side effects, lower toxicity, and a variety of modes of action. The goal of this work is to present a theoretical overview of natural compounds with antiviral activity against HSV; flavonoids (Linarin, Diosmin, Hyperoside, Kaempferol-3-O-glucuronide, Kaempferol-3-Oarabinoside) and phenolic acid (Chlorogenic acid) had a higher energy binding score than Acyclovir in the current study, so it would be interesting to separate them using chromatographic techniques and detect them using authentic sample, 1D and 2D NMR spectroscopy. Further in vivo studies on these flavonoids and chlorogenic acid could reveal more about their antiviral efficacy. Based on these findings, flavonoid phytochemicals and chlorogenic acid have the potential to be efficient antiviral medications.

Funding: This research received no external funding.

Conflicts of Interest: The authors declare no conflicts of interest.

Acknowledgments: The authors would like to extend their sincere appreciation to all members of Pharmacognosy Department (Al-Azhar University (Girls) and Dr. Therese Labib, Botanical specialist, (Department of Flora, and taxonomy) Al-Orman garden for identifying the plant under investigation.

Author Contributions: all authors reviewed the literature, drafted the manuscript, critically revised, and approved the final version before submission. All authors have read and agreed to the published version of the manuscript.

Acknowledgments: In this section you can acknowledge any support given which is not covered by the author contribution or funding sections. This may include administrative and technical support, or donations in kind (e.g., materials used for experiments).

\section{List of Abbreviations:}

LC-ESI-QTOF-MS/MS: Liquid chromatographyelectrospray ionization -quadrupole time of flight mass spectrometry; MOE: Molecular Operating
Environment; Rt: Retention time; m/z: Major product ions.

\section{REFERENCES}

1. Arduino PG, Porter SR. Herpes Simplex Virus Type 1 infection: Overview on relevant clinico- pathological features. J Oral Pathol Med. 2008;37(2):107-21.

2. El-Toumy SA, Salib JY, El-Kashak WA, Marty C, Bedoux G, Bourgougnon N. Antiviral effect of polyphenol rich plant extracts on herpes simplex virus type 1 . Food Sci Hum Wellness [Internet]. 2018;7(1):91-101. Available from: https://doi.org/10.1016/j.fshw.2018.01.001

3. Hayes RP, Heo MR, Mason M, Reid J, Burlein C, Armacost KA, et al. Structural understanding of non-nucleoside inhibition in an elongating herpesvirus polymerase. Nat Commun [Internet]. 2021;12(1):1-7. Available from: http://dx.doi.org/10.1038/s41467-02123312-8

4. Kitazato K, Wang Y, Kobayashi N. Viral infectious disease and natural products with antiviral activity. Drug Discov Ther [Internet]. 2007;1(1):14-22. Available from:

http://www.ncbi.nlm.nih.gov/pubmed/225 04360

5. Rizwani GH, Mahmud S, Shareef $H$, Perveen R, Ahmed M. Analgesic activity of various extracts of Holoptelea integrifolia (Roxb.) Planch leaves. Pak J Pharm Sci. 2012;25(3):629-32.

6. Mondal S, Bandyopadhyay A. The wonders of a medicinal tree: Holoptelea integrifolia (ROXB.) planch. Int J Pharm Pharm Sci. 2016;8(8):43-8.

7. Sinha D. Pharmacological Importance of Polyphenols: a Review. Vol. 10, International Research Journal Of Pharmacy. 2019. p. 13-23.

8. El FSA, Mohammed HS, Ibrahim MH, Ismaail LD. Chemical profiling of polyphenols in Thunbergia alata and in silico virtual screening of their antiviral activities against COVID-19. 2021;1(2):94-100. 
9. Al-yousef HM, Hassan WHB, Abdelaziz S, Amina M, Adel R, El-sayed MA. Antidiabetic, and Antiobesity Activities of the Aqueous Extracts of. 2020;(June).

10. Abaneda ÄN. Separation and Characterization of Phenolic Compounds in Fennel ( Foeniculum vulgare ) Using Liquid Chromatography - Negative Electrospray Ionization Tandem Mass Spectrometry. 2004;

11. Ibrahim LF, Elkhateeb A, Marzouk MM, Hussein SR, Kassem MES. Flavonoid investigation, LC - ESI-MS profile and cytotoxic activity of Raphanus raphanistrum L . ( Brassicaceae ). 2016;8(7):786-93.

12. Schreb GV, Elvira M, Martucci P, Vos RCH De, Carollo CA, Gobbo-neto L. Metabolomics as a Potential Chemotaxonomical Tool: Application in the Metabolomics as a Potential Chemotaxonomical Tool: Application in the Genus Vernonia Schreb. 2014;(April).

13. Olennikov D, Chirikova NK. Rhamnetin Glycosides from the Genus Spiraea. 2018;(February):10-5.

14. Zeng Y, Li S, Wang X, Gong T, Sun X, Zhang Z. Validated LC-MS/MS Method for the Determination of Scopoletin in Rat Plasma and Its Application to Pharmacokinetic Studies. 2015;189889001.

15. Lopez-avila V, Yefchak G. Mass Spectral Fragmentation Studies of Coumarin-Type Compounds Using GC High-Resolution MS. 2011;27-36.

16. Mena P, Calani L, Galaverna G, Bruni R, Crozier A, Rio D Del. Rapid and Comprehensive Evaluation of (Poly)phenolic Compounds in Pomegranate ( Punica granatum L.) Juice by UHPLCMS. 2012;14821-40.

17. Oszmian J. Application of ultraperformance liquid chromatographyphotodiode detector- quadrupole / time of flight-mass spectrometry ( UPLC-PDA-Q /
TOF-MS ) method for the characterization of phenolic compounds of Lepidium sativum L . sprouts. 2013;699-706.

18. Lin $\mathrm{Y}, \mathrm{Xu} \mathrm{W}$, Huang M, Xu W, Li H, Ye $\mathrm{M}$, et al. Qualitative and quantitative analysis of phenolic acids, flavonoids and iridoid glycosides in Yinhua Kanggan tablet by UPLC-QqQ- MS/MS. Molecules. 2015;20(7):12209-28.

19. Jarrell TM, Marcum CL, Sheng H, Owen BC, O'Lenick CJ, Maraun $\mathrm{H}$, et al. Characterization of organosolv switchgrass lignin by using high performance liquid chromatography/high resolution tandem mass spectrometry using hydroxide-doped negative-ion mode electrospray ionization. Green Chem. 2014;16(5):2713-27.

20. Kumar Trivedi M. Evaluation of Isotopic Abundance Ratio in Biofield Energy Treated Nitrophenol Derivatives Using Gas Chromatography-Mass Spectrometry. Am J Chem Eng. 2016;4(3):68.

21. Pandey S, Kumar J, Srivastava NK, Dutt S. Homology Modeling of DNA polymerases of Herpesviridae family and structure-based virtual screening for inhibitor identification. J Appl Pharm Sci. 2015;5(12):48-55.

22. Liu S, Knafels JD, Chang JS, Waszak GA, Baldwin ET, Deibel MR, et al. Crystal structure of the herpes simplex virus 1 DNA polymerase. J Biol Chem. 2006;281(26):18193-200.

23. Molecular Operating Environment (MOE) 2014, Chemical Computing Group Inc., Montreal, Canada, http://www.chemcomp.com .

24. Grover A, Agrawal V, Shandilya A, Bisaria VS, Sundar D. Non-nucleosidic inhibition of Herpes simplex virus DNA polymerase: Mechanistic insights into the anti-herpetic mode of action of herbal drug withaferin A. BMC Bioinformatics [Internet]. 2011;12(SUPPL. 13):S22. Available from: http://www.biomedcentral.com/1471$2105 / 12 / \mathrm{S} 13$ 